\section{ES IMPOSIBLE NO}

\section{COMUNICAR}

\section{Joan Costa y Solá-Segalés}

Doctor en comunicación visual

Master Internacional DirCom on-line. Universidad Católica San Antonio. Campus de los Jerónimos, s/n Guadalupe, 30107 Murcia (España) - Email: joancostasola@gmail.com

\section{Resumen}

La confusión entre "comunicar" y "significar" proviene del hecho de que la comunicación transporta significados, pero también se producen significados fuera del proceso de comunicación. Es lo que llamamos "semiosis no comunicativa".

Es tan inútil una teoría sin práctica como una práctica sin teoría. Sin práctica, una teoría no es más que palabras. Sin teoría, la práctica acaba en simple técnica. Por esto, quienes estamos todo el tiempo con problemas de estrategia y táctica empresarial con la vista puesta en los resultados, y al mismo tiempo estamos en la investigación y en la formación universitaria, no podemos perder el hábito de teorizar. Crear teoría es el gran placer de la inteligencia. Por eso hoy me he propuesto teorizar.

\section{Palabras clave}

Comunicación, semiótica, código, semántica, sintáctica, pragmática,

signo, mensaje, significado,

semiosis no comunicativa

\section{Key Words}

Communication, semiotics, code, semantics, syntactic, pragmatics,

sign, message, meaning, not communicative semiosis

\section{Abstract}

The confusion among "communicate" and "mean" comes from the fact that communication conveys meaning, but meaning is produced outside the communication process. It is what we call "not communicative semiosis." 


\section{Introducción}

"Es imposible no comunicar". Esta afirmación, corriente entre profesionales y estudiantes, tiene en sí misma un peso absoluto de convicción que nadie se atreve a discutir. Preguntémonos en primer lugar por qué. De entrada, porque existe -por lo menos en estado latente- la convicción generalizada de que todo comunica. Parece que todo lo que existe a nuestro alrededor, lo animado y lo inanimado, lo voluntario y lo involuntario, lo propio y lo ajeno nos están enviando constantemente señales, y que esto es inevitable. Tal es la creencia.

Dado que eso creemos, o estamos dispuestos a creer, cuando se dice "es imposible no comunicar" sentimos que se nos está dando la razón. Nada que objetar, porque "todo comunica”. Pero antes de seguir adelante, también debemos preguntarnos por qué creemos eso que creemos. Mi hipótesis es que hay dos motivos de fondo.

\section{Objetivos}

- Estudiar las relaciones entre teoría y práctica en el ámbito de la comunicación.
- Analizar la expresión y demostrar su valor semántico de "es imposible no comunicar"

\section{Metodología}

Teoría de la comunicación a la luz de la semiótica.

\section{Psicología de la centralidad}

El primer motivo es una cuestión psicológica. Es la tendencia a "hominizar" las cosas, humanizarlas: ellas me hablan, me envían sus mensajes. Esta tendencia un poco animista está ligada a la psicología de la centralidad: yo soy el centro del mundo (cada uno es el centro del mundo), y a mi alrededor, las cosas del mundo se organizan escalonadamente a través de la distancia - e inversamente, de la proximidad- en relación a mi posición central. Así, el mundo se presenta en perspectiva y lo que está cerca en principio me afecta más que lo que sucede lejos. Esta es la ley proxémica en 
psicología. Pero la distancia o cercanía de las cosas respecto a mí no sólo es una dimensión física o geométrica, sino sobre todo psicológica y, por tanto, emocional. Ser cada uno centro del mundo (de su mundo) es esencial por referencia a las cosas y los seres del entorno. Si yo no fuera el centro, ¿cómo podría entender el mundo?

Hasta aquí quedaría explicado teóricamente el por qué las cosas del entorno me envían señales, signos, mensajes. Si "todo comunica”, a pesar incluso de sí mismo, entonces “es imposible no comunicar". Pero incluso estos argumentos de la psicología de la centralidad no bastan para explicar nuestra reacción conformista ante esta afirmación. Tenemos que considerar también una segunda razón que se imbrica con la anterior. Es la fuerza de las palabras: la capacidad de convicción o de seducción que tienen las palabras. Analicemos pues la construcción de esta frase "es imposible no comunicar" y veamos por qué ella misma nos impone tal fuerza de pregnancia.

\section{Retórica de la convicción}

En efecto, la frase en cuestión suena a desafío y, al mismo tiempo, tiene la apariencia de una paradoja. O de una verdad que no admite discusión. Tiene un acento intimidatorio por su contundencia. Sorprende, porque juega afirmando una cosa a través de una doble negación: afirma lo que es mediante un "imposible" y un "no". Y cierra así toda otra posibilidad. Esta exclusión explícita, que rechaza todo razonamiento, implica una consecuencia que, llevada al extremo, resultaría atroz: si todo lo que existe en el entorno, incluido yo mismo, está condenado a comunicar, entonces yo no soy dueño de mis actos, pues no puedo evitar estar constantemente emitiendo señales y signos. Todos seríamos una especie de máquinas incontrolables que emiten mensajes sin cesar. En este aspecto, el designio humano sería comunicar contra la voluntad de uno mismo.

La frase en cuestión "es imposible no comunicar" funciona como un axioma y una paradoja a la vez; primero por lo que el axioma tiene de imperativo y segundo porque al mismo tiempo, desconcierta. Se cierra así toda reacción dialéctica. La frase es rotunda, redonda. Gira sobre sí misma y deja la afirmación en el aire, como si todo estuviera ya dicho. No va más allá, ni nos deja.

Así que, al margen de si lo que se afirma aquí es verdadero o falso (es imposible no comunicar), lo que hemos examinado es el por qué esta frase convence y no admite discusión. Hemos visto cómo los mecanismos psicológicos de la centralidad individual y los mecanismos retóricos de la convicción 
se refuerzan recíprocamente, y así entenderemos por qué el enunciado "es imposible no comunicar" se impone como una verdad indiscutible. Pero...

\subsection{La comunicación a la luz de la semiótica}

Lo que sucede es que la idea se había entendido mal. Lo que Paul Watzlawick escribió no es eso exactamente, sino "es imposible no comunicarnos". ${ }^{\text {i }}$ Ese "nos" final lo cambia todo, como veremos. $\mathrm{Y}$ el autor añade: "el aspecto relacional de tal comunicación subraya aún más este argumento". ii Obsérvese un dato importante y que ha pasado desapercibido: Watzlawick, ya la primera palabra del título original de su libro, hace referencia al aspecto pragmático de la comunicación humana (término de la semiótica que es crucial en el discurso del autor y que la traducción española ha obviado). La palabra "pragmática" define el contexto en el que hay que entender el significado, al situarlo exactamente en el tercer principio de la Semiótica.

Con el objeto de precisar el marco conceptual del que se sirve Watzlawick recordemos algunos puntos esenciales de la semiótica:

1. Semiótica es el estudio general de los signos, partiendo de la premisa de que es "signo" todo aquello que "significa" algo para alguien. (No confundir con la semiología, que es el estudio exclusivo de los signos lingüísticos).
2. Semiosis designa el proceso de percepción por el cual se forma el significado en la mente a partir de un estímulo dado: un signo.

3. Los principios semióticos básicos a los que nos referimos son:

- la semántica, parte de la semiótica que estudia las relaciones de los signos con los significados;

- la sintáctica, que se ocupa de las relaciones entre los signos en el interior de un código o de un discurso;

- la pragmática, que estudia las relaciones de los signos con los individuos por medio de la observación de sus reacciones. (Retomaremos estas ideas dentro de un momento).

En efecto, no es lo mismo afirmar que "es imposible no comunicar” -que puede aplicarse a un medio masivo unidireccional como la televisión que emite las 24 horasque precisar "es imposible no comunicarnos”, que se refiere explícitamente a nosotros, comunicantes humanos y al carácter relacional de esta clase de comunicación.

El pensamiento de Watzlawick se remonta a la raíz misma de los humanos como seres sociales. Que lo son en la medida que se relacionan y se comunican entre ellos. Tal como observó Abraham Moles hace ya varias décadas, lo que llamamos tradicionalmente "sociedad" se ha convertido en un sistema social. Éste no se define como tal por la suma de individuos que pueblan un territorio (eso sería la "población”), sino por las 
interacciones y las relaciones que los vinculan entre ellos.

La idea de Watzlawick tiene en cuenta, fundamentalmente, este impulso irrefrenable del ser humano por relacionarse con el Otro, expresarse mutuamente, intercambiar ideas y experiencias, disentir, cooperar, etcétera. Todas las especies zoológicas impulsan a los individuos a comunicarse, con lo cual se forman los grupos y las sociedades. Es lo propio de los seres que viven en comunidad, en común. Una comunidad humana existe por lo que los individuos que la conforman tienen en común: una lengua, unos códigos, una cultura, un sentimiento de identidad. No hay comunidad sin comunicación, y ésta existe en la medida que nosotros la podemos formular y expresar, y recíprocamente la podemos aceptar o rechazar.

\subsection{La semiosis comunicativa}

Ahora bien, esta versión mutilada de la idea de Watzlawick que declara la imposibilidad de "no comunicar", se encuadra en la parte de la semiosis que mi amigo profesor de la Universidad Técnica de Berlín, Roland Posner, llama con toda precisión "la pragmática de la semiosis no comunicativa, Lo cual indica que existe formación de significados en la mente de uno, incluso fuera de un proceso de comunicación. O sea, significados que no han sido elaborados ni transmitidos de una mente a otra. ¿Cómo funciona la formación de sentido sin una fuente emisora ni un código? Por medio de nuestras percepciones de signos naturales, o sea sin la mediación de un emisor ni de codificación. ¿Cuál es entonces la diferencia entre la formación de significados dentro de un proceso de comunicación y fuera de él?

En el proceso comunicacional, el emisor tiene intención de enviar un mensaje a un receptor. Para lo cual elige un código apropiado, es decir, compartido (supongamos el de la escritura), y selecciona unas palabras (significante) asociadas al mensaje proyectado. Puesto que el significado entra en correlación con ese significante correspondiente por medio del código, el emisor ha producido un signo, que es desencadenante de ese significante. Por su parte, el receptor percibe el signo gracias al medio o canal (visual, auditivo, táctil, etc.) y lo toma como equivalente del significante, que le remite al significado a través del código. Así, el receptor reconstruye el mensaje (el contenido) a partir del significado, y con la ayuda de las indicaciones procedentes de la situación compartida por ambos comunicantes: el medio y el contexto, pues éstos intervienen también en la formación del significado. Esta descripción puede ser expresada esquemáticamente como sigue: 


\section{Gráfico ${ }^{\circ} 1$ Componentes de la semiosis} en el proceso de comunicación

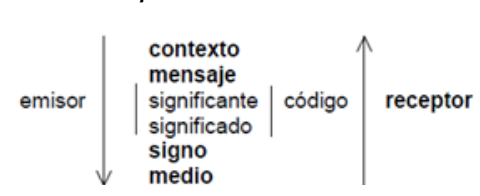

Las palabras en negritas indican que son necesarias y suficientes para que la semiosis tenga lugar. La flecha de la izquierda indica el orden de la secuencia por parte del emisor y la flecha de la derecha indica la del receptor.

Fuente: Elaboración propia

\subsection{Signo $y$ contexto}

La mente está constantemente activa en el entorno espaciotemporal que nos envuelve, y que es un continuo de cosas y fenómenos (el contexto). Nuestro sistema sensorial tiene la capacidad separadora, es decir, la aptitud por discriminar elementos del entorno y focalizar su atención en ellos. Estos elementos son los estímulos que excitan la atención o el interés. Son signos, entendidos como "unidades portadoras de sentido". La actividad constante de la mente es una especie de escáner que ejerce un "barrido" del entorno de estímulos, lo que conlleva una selección: un interlocutor que me interesa o que no puedo evitar; un objeto, una cosa, un fenómeno, que me atraen y en los cuales me concentro.

De hecho, el entorno que nos rodea -y del que somos el centro- está hecho de seres humanos y de otros seres vivos, y también, como he indicado, de objetos fabricados por el hombre (macro y micro objetos); de cosas y fenómenos naturales (paisajes, rocas, puestas de sol, etc.), y de acontecimientos sociales (eventos). En este sentido, existe una oposición, y una colaboración al mismo tiempo, entre el entorno natural (la Naturaleza predecesora) y el entorno artificial, superpuestos. Es decir que existe una dialógica entre Naturaleza y Artificio, entre Biología y Cultura.

El ser humano inserto en ese entorno se relaciona, voluntaria o aleatoriamente, con los elementos que están y se producen en él. Y en ese cara a cara, lo natural y lo artificial, lo programado y lo contingente también producen "signos" para el ser humano. Y aunque no existe un proceso de comunicación entre él y las torres del tendido eléctrico, las nubes o su propia sombra, sí existe la formación de significados a partir de estos signos. Hay semiosis.

\section{Conclusiones. La semiosis no comunicativa}

Ya sólo nos queda casar tres conclusiones:

1. el significado se produce, también, fuera del proceso comunicativo, ya que en nuestro mundo todo puede ser signo de algo para alguien,
2. todo signo significa algo que siempre está fuera de él: cosas ausentes que sólo se hacen presentes a la conciencia en tanto que significado (el hombre es un animal simbólico), y 
3. el significado no está en los signos sino potencialmente, y cristaliza en la mente que lo produce al interpretarlo; pero esta investidura de significado que influye en el propio ser, deja intacto el signo.

Hechas estas consideraciones generales pero conclusivas, volvamos al esquema anterior, que nos ayudará a explicar la pragmática de la semiosis no comunicativa por comparación con la semiosis comunicativa.

El anterior esquema muestra en su conjunto los elementos de la acción comunicativa, y al mismo tiempo, el proceso de producción de significado, cuyo orden es inverso en el caso del emisor y del receptor.

Si hacemos ahora una lectura de ese esquema, pero sólo de los términos destacados en negritas y nos olvidamos del resto, podremos visualizar los elementos que intervienen en la semiosis no comunicativa y en su proceso.

En este caso, el receptor del estímulo (cosa o fenómeno) es el único protagonista. A través del medio visual, auditivo u otro, el individuo percibe ese estímulo que, para él es signo de algo, y lo interpreta como un mensaje o un significado de algo ausente. El contexto en el que se produce el cara a cara incide asimismo en la semiosis. En síntesis, la diferencia entre el proceso comunicativo y el no comunicativo es que en este último no hay emisor intencional, ni código interpuesto.
Veamos un ejemplo. El individuo sale de casa y percibe un signo: "nubarrones", que en ese contexto, para él es un mensaje: "lloverá". La pragmática semiótica se manifiesta en la reacción del individuo, que vuelve en busca del paraguas.

Otro ejemplo de semiosis no comunicativa surge esta vez en el proceso de una semiosis de comunicación "manipulatoria", donde nuestro interlocutor esconde sus cartas. Se trata de una comunicación interpersonal cara a cara en la cual se superponen el mensaje verbal intencional y el mensaje no verbal, pero donde ambos tienen la intención de convencer $y$, por eso, con los gestos se subrayan las palabras. Pero también hay una acción no intencional subyacente que revela lo que las palabras quieren ocultar. Esta situación quedó bien explicada por Nietzsche: "la boca puede mentir, pero la mueca que se hace en ese momento revela, sin embargo, la verdad”. Las expresiones faciales y otros signos involuntarios dan a entender lo que las palabras quieren ocultar. El emisor sólo ha codificado y verbalizado lo que quiere significar, pero no ha podido evitar que su interlocutor descubra lo que no quiere que sepa: que le está engañando. Se llama a eso comunicación manipulatoria, y en ella intervienen, y se contradicen, una semiosis comunicativa y una semiosis no comunicativa. Pero el resultado es que, en ambos casos, hay producción de significados en la mente del receptor. Lo que sucede es que el significado de las palabras se produce de un modo (comuni- 
cativo) y el significado de los signos involuntarios lo hace de otro modo (no comunicativo). Son dos modos distintos dentro del proceso: de comunicación y de no comunicación.

Esto es, precisamente, lo que se confunde cuando se afirma que "todo comunica". Lo cierto es que no todo comunica, pero sí todo significa.
Entonces, una afirmación verdadera es que "es imposible no comunicarnos". La otra es que "es imposible no significar". Todo significa. Incluso lo que no significa significa que no significa. Es la aportación de la semiótica a la teoría de la comunicación en la búsqueda de sus efectos psicológicos y sociales.

\section{Referencias}

WATZLAWICK, Pragmatics on Human Communication, W. W. Norton \& Co. 1967. Versión castellana: Teoría de la comunicación humana, Tiempo Contemporáneo, Buenos Aires, 1971.
POSNER, R., Qu'est-ce-que la Pragmatique, Voyes Libres, Lyon, documento personal sin fecha

\section{NOTAS}

${ }^{i}$ P. Watzlawick, Pragmatics on Human Communication, W. W. Norton \& Co. 1967. Versión castellana: Teoría de la comunicación humana, Tiempo Contemporáneo, Buenos Aires, 1971.

ii op. cit.

${ }^{\text {iii }}$ R. Posner, Qu'est-ce-que la Pragmatique, Voyes Libres, Lyon, documento personal sin fecha. 